\title{
ARTICLES
}

\section{ABOUT THE ROLE OF IMMUNO-INFLAMMATORY MECHANISMS IN THE PATHOGENESIS OF ATHEROSCLEROSIS}

\author{
${ }^{1,2}$ Chaulin A.M., ${ }^{2}$ Grigoryeva Yu.V., ${ }^{1,2}$ Duplyakov D.V. \\ ${ }^{1}$ Samara Regional Clinical Cardiology Dispensary, Samara; \\ ${ }_{2}^{2}$ Samara State Medical University, Samara,e-mail: alekseymichailovich22976@gmail.com \\ Studying the role of immune-inflammatory mechanisms in pathogenesis of atherosclerosis is considered to be \\ one of the most important scientific-research directions and has a rather rich history. According to the modern data, \\ immune-inflammatory mechanisms, along with disturbance in lipid metabolism (dislipidemy) and disfunction of en- \\ dothelium play a key role in development and progression of atherosclerosis and cardiovascular diseases. A close rela- \\ tion between immune-inflammatory mechanisms and dislipidemy, as well as endothelium disfunction is confirmed by \\ numerous experimental and clinical studies. Immuno-inflammatory mechanisms contribute to pathogenesis if athero- \\ sclerosis significantly and deserve our acute attention. At the early stage of accumulation of cholesterin, lipoproteins of \\ low density, and oxidated lipoproteins of low density on the vascular wall happens along with activation of endothelial, \\ inflammatory, and immune-competent cells. Immuno-competent cells that arrived to the focal area of atherosclero- \\ sis, produce a line of cytokines and chemokines, thus attracting new leukocytes and providing for development of \\ atherosclerosis. Among inflammatory and immune-competent cells macrophages, dendrite cells, T-lymphocytes, and \\ also their subpopulations play the most important part in development of atherosclerosis. In this literature review we \\ gradually study the role of these cells in pathogenesis of atherosclerosis, discuss complex interactions between lipid \\ metabolism, endothelial, inflammatory, and immuno-competent cells in event of atherosclerotic damage of vessels.
}

Keywords: cardiovascular diseases, atherosclerosis, immune-inflammatory mechanisms, macrophages, dendritic cells, T-lymphocytes

Since atherosclerosis is the major cause of development and progression of cardiovascular diseases, studying pathogenetic mechanisms, underlying it, is one of the most urgent scientific-research directions. Studying pathophysiology of atherosclerosis does not only draw our theoretical interest, but also has a significant practical value, as it provides for search of new diagnostic biomarkers and targets for therapeutic impact [1-4].

History of studying the role of immuneinflammatory mechanisms in development of atherosclerosis, as well as the history of formation of lipid hypothesis of atherosclerosis (A.I. Ignatovskiy, N.N. Anichkov, S.S. Khalatov), is rather rich [5]. The first data on relation between atherosclerosis and inflammation can be found in works by researchers Rayer and R. Virkhov, dated more than 150 years ago [6]. A close relation between inflammation and atherosclerosis was registered at cellular and tissue level of organization. Thus, for example, in case of inflammation, as well as atherosclerosis, the same cells of connecting tissue were discovered: endotheliocytes, fibroblasts, smooth muscle cells (SMC), macrophages, neutrophils, and also T- and B- lymphocytes $[6,7]$. Later, along with development of research methods, close relations between atherosclerosis and inflammation were discovered at molecular level of organization. Thus, in event of inflammation and atherosclerosis it was discovered that formation of inflammatory molecules - cytokines (interleukines-1, 6 etc.) and proteins of acute phase (C-reactive protein, fibrinogen, haptoglobin, etc.) intensified [6].
Researchers underline that inflammation and atherosclerosis depend on the same functional reactions and presence of atherosclerosis within symptomatic complex of atherosclerosis should not be underestimated [6].

Immuno-inflammatory mechanisms of atherogenesis are closely relates to disturbance in lipid metabolism and disfunction of endothelium $[7,8,9]$. Immuno-inflammatory mechanisms that participate in pathogenesis of atherosclerosis, play in important part in all phases of its development. The early stage of atherosclerosis is considered as an inflammatory reaction to oxidated lipoproteins of low density (ox-LPLD) [7]. In this phase, due to condition of hypercholesteremia infiltration and accumulation of LPLD in vessel walls increases, and it results in activation of endothelial and immune-inflammatory cells due to release of pro-inflammatory factors $[7,8,10]$. Expression of molecules of leucocyte adhesion intensifies adhesion of leucocytes and results in leucocytic infiltration of vessel walls [11]. These leucocytes release chemo-attracting stimulus, including chemokines that attract additional monocytes and leucocytes to the atherosclerotic focus area. Thus, the produced monocytic chemotactic protein-1 (MCP-1) attracts leucocytes that carry chemokine receptor (CCR)-2, including monocytes and T-lymphocytes [12, 13]. Interferon (IFN)- $\gamma$-induced protein 10 (IP-10), also known as chemokine CXCL10, IFN- $\gamma$-induced alpha chemo-attractant of T-cells (I-TAC/CXCL11), monokine, induced by IFN- $\gamma$ (MIG or chemokine CXCL9), selectively attract $\mathrm{T}$ and B-lymphocytes that carry 
CXC-receptor CXCR3 [14,15]. Chemokine CX3CL1 (fractalkine) that is a membrane-connected chemokine, also provides for attraction of monocytes to vessel walls and stimulates differentiation of monocytes into macrophages at early stage of atherosclerosis development [16]. In their turn, macrophages play an important part in initiation of inflammation and ignition of immune response within atherosclerotic patch $[7,8]$. Within focus point of atherosclerotic inflammation macrophages, dendric cells, T-lymphocytes and their subpopulations, B-lymphocytes, and cloud cells are found most frequently. Further we shall study their role in pathogenesis of atherosclerosis.

\section{Macrophages}

Monocytes are linked to endothelial cells via interaction between monocytal P-selectine of glycoprotein ligand-1 (PSGL-1) and endothelial P-selectine [17]. For adhesion and diapedesis monocytes express integrin $a 4 \beta 1$, also known by name "very late antigen-4" (VLA-4) and lymphocytal functional antigen-1 (FLA-1), with their help they are linked to ligands of endothelial cells, including molecule of vascular endothelium adhesion (VCAM-1) and molecule of inter-cellular adhesion ICAM-1 [17]. Monocytes that migrated to vessel wall, differentiate into macrophages via mediators: monocytic colony-stimulating factor (M-CSF) and granulocyte-monocytic colony-stimulating factors (GM-CSF). Macrophages use patternrecognizing receptors (PRR), including scavenger-receptors (SR) and Toll-like receptors (TLR), such as transmembrane proteins SR-A (CD204), CD36, receptor of macrophages with collagen structure (MARCO) and lectin-like receptor ox-LPLD (LOX-1/OLR-1) for capturing (internalization) of endotoxins, apoptotic bodies, and particles of LPLD and ox-LPLD [18, 19]. Two basic phenotypes of macrophages are distinguished: macrophages M1 (anti-inflammatory/classically activated macrophages). Macrophages M1 enable inflammation by secreting pro-inflammatory cytokines, and phagocyte antigens, presenting them with T-lymphocytes via PRR which results in release of big number of pro-inflammatory cytokines, including IL-1, IL-6, IL12- IL-15, IL-18, migration of inhibiting factor (MIF) and factor of necrosis of tumor-alpha (FNT- $\alpha$ ), that enable activation of T-lymphocytes. Macrophages M2 possess antiinflammatory functions and remove inflammation of patches due to efferocytosis (phagocyte of apoptotic bodies) and release of cytokines with T-helpers of type 2 (Th2), such as IL-4, IL-10, and IL-13 [17, 18, 19].
It is shown that in event of atherosclerotic damage the transforming factor of growth-beta (TGF- $\beta$ ), extracted from macrophages, plays an important part in vessel biology, impacting processes of proliferation, differentiation, migration, and apoptosis of cells, as well as production of outer-cell matrix components [20]. TGF- $\beta$ regulates both vasodilatation and vasoconstriction through signal path TGF- $\beta$ /ALK5/ Smad3 by inducing expression of endothelin-1 in endothelial cells and also by decreasing migration and proliferation of endothelial cells $[20,21]$. S Xu and co-authors reports that TGF- $\beta$ also carries out pro-atherosclerotic function due to increasing proliferation of SMC [21]. Anti-atherosclerotic function of TGF- $\beta$ consists in decreasing recruitment of inflammatory cells, adhesion of thrombocytes, and suppression of macrophage activation [21]. Thus, summarizing major effects of TGF- $\beta$ according to results of a line of studies, we should outline that TGF- $\beta$ has a bi-functional (pro-atherogenic and anti-atherogenic) effect upon pathogenesis of atherosclerosis [20,21].

Receptors of macrophages TLR link effector molecules and initiate signal cascade that enables activation of macrophages with further formation of inflammatory cytokines, proteas, and cytotoxic radicals of oxygen and nitrogen by them. A similar activity is observed in dendrite cells (DC), cloud and endothelial cells that also contain TLR [22]. Vessel endothelium growth factor (VEGF) is also released from macrophages and enables angiogenesis [22]. Accumulation of cholesterin takes place in macrophages after consumption of ox-LPLD via scavenger-receptors, including CD36, SR-A1, and LOX-1. Ethers of cholesterin are hydrolyzed, and molecules of ox-LPLD are catabolized by endosomes and lysosomes of macrophages. In normal conditions within endoplasmic reticulum ferment acyl-KoAcholesterin-acyltransferase (AKAT) etherifies free cholesterin and accumulates (preserves) it in lipid drops. In event of atherosclerosis lipid homeostasis in macrophages is disturbed and causes formation of foam cells. Apoptosis of foam cells is induced by prolonged "stress" of endoplasmic reticulum due to exceeding accumulation of cholesterin. It results in secondary necrosis of cells and formation of necrotic core of atherosclerotic patch. Besides, macrophages secret FNT-a and nitrogen oxide, thus igniting Fas-mediated apoptosis in SMC. Macrophages also decrease synthesis of collagen in SMC and destroy elements of outer-cell matrix with matrix metalloprotease (MMP), especially MMP-2 and MMP-9. Death of SMC and 
weakening of outer-cell matrix cause tear of atherosclerotic patch, and it results in exposure of thrombogenic substances of sub-endothelial layer which causes adhesion and aggregation of thrombocytes in this part of vessel [17, 21, 22].

\section{Dendrite cells}

Dendrite cells (DC) are a family of antigen-presenting cells that express high levels of molecules of the main complex of histocompatibility of class II (MHC II) and provide for inborn and obtained immune response, presenting endogenic and exogenic antigens with T-lymphocytes [19, 23]. Life cycle of DC consists of three stages. In bone marrow predecessors of dendrite cells are differentiated into classic dendrite cells $(\mathrm{cDC})$ via transmitting signals of FMS-like tyrosine kinase 3 (FLT3) and FLT-3-liganda. Then cDC are differentiated either into lymphoid-resistant $\mathrm{CD} 8^{+} \mathrm{cDC}$ or into non-lymphoid $\mathrm{CD} 103^{+} \mathrm{cDC}$ [24]. In lymphoid tissue $\mathrm{CD} 8^{+} / \mathrm{CD} 103^{+} \mathrm{cDC}$ play the deciding role in development of $\mathrm{CD} 8^{+} \mathrm{DC}$ vie cross-presentation of antigens of $\mathrm{CD} 8^{+}$to $\mathrm{T}$ cells. In non-lymphoid tissues $\mathrm{CD} 11 \mathrm{~b}^{+} \mathrm{DC}$ are located, and they are similar to their functions to lymphoid $\mathrm{CD}^{+} / \mathrm{CD} 103^{+} \mathrm{cDC}$ [24].

In event of atherosclerotic damage of vessels DC is attached to the activated endothelium with help of adhesion molecules, including P-selectin, E-selectin, and VCAM-1 [25]. After consumption of lipids and other antigens DC present them to T-lymphocytes via co-stimulating molecules - CD40, CD80, and CD86 [26, 27]. It is shown that interaction between antigens and TLR of DC results in intensification of emission of various inflammatory cytokines, including IL-6, FNT-a, IL-12, IL-23, and GMCSF [28]. Foam cells are phagocyted by macrophages or immature DC that also transform in foam cells after consumption of lipids and efferocytosis [29]. Mature CD11b ${ }^{+} \mathrm{DC}$, activated by ox-LPLD and PAMP, inhibit regulatory T-cells (T-suppressors) [30]. In experimental research on mice it was shown that chemokine CCL17, produced by DC, intensify atherogenesis, supposedly by activating $\mathrm{CD} 4^{+} \mathrm{T}$-cells and spreading inflammatory processes. During inhibiting chemokine CCL17 with specific anti-bodies, inflammatory reaction and atherogenesis slowed down, due to it this chemokine is studied only as a perspective target for developing anti-atherosclerotic medication [31].

\section{T-lymphocytes and their subpopulations}

T-lymphocytes are attracted to inflammation focus point via the same mechanisms as monocytes, by molecules of adhesion and chemokines. Several populations of T-lymphocytes are discovered in atherosclerotic patches during morphologic research. The migrated Tcells are activated by antigens, represented by antigen-presenting cells (APC) (macrophages and DC) through two signals. First of all, linking of antigen receptors at the surface of APC initiates a response to PAMP that are molecules, linked to pathogens. Molecules MHC I and MHC II interact with PAMP, such as ox-LPLD, microbal antigens, and proteins of heat shock (HSP 60) that enable protection of cells from stress damage [32]. Secondly, linking co-stimulating molecules CD28 on T-cells enables interaction with CD80 or CD86 upon APC [33, 34]. Besides, T-cells are activated via interaction between CD40-ligand (CD40L or CD154) and CD40 on APC, such as macrophages, B-lymphocytes, DC. Osteopontin, also known as protein of early T-lymphocyte activation (EAT-1)is an important stimulator of differentiating T-helper cells 1 (Th1) and is more intensively expressed by macrophages, endothelial cells and SMC in event of atherosclerotic disturbance. Th1 also enables expression of IL-12 which is a stimulator of differentiating Th1 [35]. Cytokines, produced by Th1, including IFN- $\gamma$, IL-2, FNT- $\alpha$, activate macrophages, endothelial cells, and SMC, and cause local inflammation. IFN- $\gamma$ is a pro-atherogenic cytokine and inhibitor of growth for endothelial cells and SMC [36]. It is shown that after artery damage SMC is inhibited by IFN- $\gamma$, synthesized by T-cells, and it enables destabilization and tear of atherosclerotic patch [37]. It is established that Th1 activates signal cascades, linked to expression of pro-inflammatory cytokines that stimulate production of IL-1 by macrophages. These signal paths eventually result in multiple increase in levels of FNT- $\alpha$, IL-1, IL-2, and IL-6 in focus area of atherosclerotic damage [36-39].

It was discovered that level of Th-2-specific cytokine activity is lower than Th1 in event of atherosclerotic damage, possibly due to influence of IL-12 and IL-10 [38]. However, regardless of apparent positive impact of Th2 upon atherogenesis due to the produced anti-inflammatory cytokines, Th2 also induces formation of elastolytic ferments that enable formation of aneurism [40].

$\mathrm{CD} 8^{+} \mathrm{T}$-cells represent a subpopulation of activated T-cells that display a cytotoxic activity. In case of atherosclerotic damage, after recognition of alien antigen via APC, $\mathrm{CD} 8^{+} \mathrm{T}$-lymphocytes cause apoptosis of cells via cytotoxic attack [41-43]. Death of cells result in growth of necrotic core and potentially 
enables destabilization and tear of atherosclerotic patch $[42,43]$.

\section{Conclusion}

Thus, immune-inflammatory mechanisms play an important role in development of atherosclerosis. According to modern data, monocytes/macrophages, dendrite cells, T-lymphocytes and their subpopulations participate in pathogenesis of atherosclerosis. Complex interactions between these cells in process of atherogenesis remain an object of our studies. In perspective immune-inflammatory mechanisms represent a promising target in terms of developing anti-atherosclerotic medication.

\section{References}

1. Chaulin A.M., Karslyan L.S., Grigoriyeva E.V., Nurbaltaeva D.A., Duplyakov D.V. Clinical and Diagnostic Value of Cardiac Markers in Human Biological Fluids. Kardiologiia. 2019. vol. 59. no. 11. P. 66-75. DOI:10.18087/cardio.2019.11.n414.

2. Aronov D.M., Lupanov V.P. Atherosclerosis and coronary heart disease: some aspects of pathogenesis. The Journal of Atherosclerosis and Dyslipidemias (JAD)-Ateroskleroz i dislipidemii. 2011. vol. 1-2. P. 48-56.

3. Chaulin A.M., Duplyakov D.V. PCSK-9: modern views about biological role and possibilities of use as a diagnostic marker for cardiovascular diseases. Part 1. Kardiologiya: novosti, mneniya, obuchenie [Cardiology: News, Opinions, Training]. 2019. vol. 7. no. 2. P. 45-57.

4. Chaulin A.M., Duplyakov D.V. PCSK-9: modern views about biological role and possibilities of use as a diagnostic marker for cardiovascular diseases. Part 2. Kardiologiya: novosti, mneniya, obuchenie [Cardiology: News, Opinions, Training]. 2019. vol. 7. no. 4. P. 24-35.

5. Parfenova N.S., Golikov Y.P., Klimov A.N. On the history of the emergence of the cholesterol model of atherosclerosis. Medical academic journal. 2016. vol. 16. no. 2. P. 7-14.

6. Yuryeva E.A., Sukhorukov V.S., Vozdvizhenskaya E.S. Novikova N.N. Atherosclerosis: Hypotheses and theories. Rossiyskiy vestnik perinatologii i pediatrii. 2014. vol. 59. no. 3. P. 6-16.

7. Gisterå A, Hansson GK. The immunology of atherosclerosis. Nat Rev Nephrol. 2017. vol. 13. no. 6. P. 368-380.

8. Chaulin A.M., Grigoryeva Yu.V., Duplyakov D.V. Modern views about the pathophysiology of atherosclerosis. Part 1. The role of impaired lipid metabolism and endothelial dysfunction (literature review). Medicine in Kuzbass. 2020. vol. 2. P. 34-41.

9. Chaulin A.M., Aleksandrov A.G., Aleksandrova O.S., Duplyakov D.V. The role of the proprotein convertase subtilisin / kexin type 9 (pcsk9) in the pathophysiology of atherosclerosis. Medicine in Kuzbass. 2019. vol. 18. no. 4. P. 5-15.

10. Kume N., Cybulsky M.I., Gimbrone M.A. Jr. Lysophosphatidylcholine, a component of atherogenic lipoproteins, induces mononuclear leukocyte adhesion molecules in cultured human and rabbit arterial endothelial cells. J Clin Invest. 1992. vol. 90. no. 3. P. 1138-1144.

11. Dai G., Kaazempur-Mofrad M.R., Natarajan S., Zhang Y., Vaughn S., Blackman B.R., Kamm R.D., GarcíaCardeña G., Gimbrone M.A. Jr. Distinct endothelial phenotypes evoked by arterial waveforms derived from atherosclerosis-susceptible and resistant regions of human vasculature. Proc Natl Acad Sci USA. 2004. vol. 101. no. 41. P. 14871-14876.

12. Boring L., Gosling J., Cleary M., Charo I.F. Decreased lesion formation in CCR2-/- mice reveals a role for chemokines in the initiation of atherosclerosis. Nature. 1998. vol. 394. no. 6696. P. 894-897.
13. Gu L., Okada Y., Clinton S.K., Gerard C., Sukhova G.K., Libby P., Rollins BJ. Absence of monocyte chemoattractant protein-1 reduces atherosclerosis in low density lipoprotein receptor-deficient mice. Mol Cell. 1998. vol. 2. no. 2. P. 275-281.

14. Haley K.J., Lilly C.M., Yang J.H., Feng Y., Kennedy S.P., Turi T.G., Thompson J.F., Sukhova G.H., Libby P., Lee RT. Overexpression of eotaxin and the CCR3 receptor in human atherosclerosis: using genomic technology to identify a potential novel pathway of vascular inflammation. Circulation. 2000. vol. 102. no. 18. P. 2185-2189.

15. Mach F., Sauty A., Iarossi A.S., Sukhova G.K., Neote K., Libby P., Luster A.D. Differential expression of three T lymphocyte-activating CXC chemokines by human atheroma-associated cells. J Clin Invest. 1999. vol. 104. no. 8. P. 1041-1050.

16. Lesnik P., Haskell C.A., Charo I.F. Decreased atherosclerosis in CX3CR1-/- mice reveals a role for fractalkine in atherogenesis. J Clin Invest. 2003. vol. 111. no. 3. P. 333-340.

17. Moore K.J., Tabas I. Macrophages in the pathogenesis of atherosclerosis. Cell. 2011. vol. 145. no. 3. P. 341-355.

18. Rizzacasa B., Morini E., Pucci S., Murdocca M., Novelli G., Amati F. LOX-1 and Its Splice Variants: A New Challenge for Atherosclerosis and Cancer-Targeted Therapies. Int J Mol Sci. 2017. vol. 18. no. 2. P. 290.

19. Alberts-Grill N., Denning T.L., Rezvan A., Jo H. The role of the vascular dendritic cell network in atherosclerosis. Am J Physiol Cell Physiol. 2013. vol. 305. no. 1. P. C1-C21.

20. Hansson G.K., Robertson A.K. TGF-beta in atherosclerosis. Arterioscler Thromb Vasc Biol. 2004. vol. 24. no. 6. P. E137-E138.

21. Xu S., Liu A.C., Gotlieb A.I. Common pathogenic features of atherosclerosis and calcific aortic stenosis: role of transforming growth factor-beta. Cardiovasc Pathol. 2010. vol. 19. no. 4. P. 236--247.

22. Falck-Hansen M., Kassiteridi C., Monaco C. Toll-like receptors in atherosclerosis. Int J Mol Sci. 2013. vol. 14. no. 7. P. $14008-14023$.

23. Van Vré E.A., Van Brussel I., Bosmans J.M., Vrints C.J., Bult H. Dendritic cells in human atherosclerosis: from circulation to atherosclerotic plaques. Mediators Inflamm. 2011. vol. 2011. P. 941396.

24. Hashimoto D., Miller J., Merad M. Dendritic cell and macrophage heterogeneity in vivo. Immunity. 2011. vol. 35. no. 3. P. $323-335$.

25. Subramanian M, Tabas I. Dendritic cells in atherosclerosis. Semin Immunopathol. 2014. vol. 36. no. 1. P. 93-102.

26. Niessner A., Weyand C.M. Dendritic cells in atherosclerotic disease. Clin Immunol. 2010. vol. 134. no. 1. P. 25-32.

27. Koltsova E.K., Ley K. How dendritic cells shape atherosclerosis. Trends Immunol. 2011. vol. 32. no. 11. P. 540-547.

28. Zernecke A. Dendritic cells in atherosclerosis: evidence in mice and humans. Arterioscler Thromb Vasc Biol. 2015. vol. 35. no. 4. P. 763-770.

29. Tabas I. Macrophage death and defective inflammation resolution in atherosclerosis. Nat Rev Immunol. 2010. vol. 10. no. 1. P. $36-46$

30. Maganto-García E., Tarrio M.L., Grabie N., Bu D.X., Lichtman A.H. Dynamic changes in regulatory T cells are linked to levels of diet-induced hypercholesterolemia. Circulation. 2011. vol. 124. no. 2. P. 185-195.

31. Weber C., Meiler S., Döring Y., Koch M., Drechsler M., Megens R.T., Rowinska Z., Bidzhekov K., Fecher C., Ribechini E., van Zandvoort M.A., Binder C.J., Jelinek I., Hristov M., Boon L., Jung S., Korn T., Lutz M.B., Förster I., Zenke M., Hieronymus T., Junt T., Zernecke A. CCL17-expressing dendritic cells drive atherosclerosis by restraining regulatory $\mathrm{T}$ cell homeostasis in mice. J Clin Invest. 2011. vol. 121. no. 7. P. 2898-2910.

32. Wick G., Jakic B., Buszko M., Wick M.C., Grundtman C. The role of heat shock proteins in atherosclerosis. Nat Rev Cardiol. 2014. vol. 11. no. 9. P. 516-529. 
33. Taleb S. Inflammation in atherosclerosis. Arch Cardiovasc Dis. 2016. vol. 109. no. 12. P. 708-715.

34. Moriya J. Critical roles of inflammation in atherosclerosis. Journal of Cardiology. 2019. vol. 73. no. 1. P. 22--27.

35. Ashkar S., Weber G.F., Panoutsakopoulou V., Sanchirico M.E., Jansson M., Zawaideh S., Rittling S.R., Denhardt D.T., Glimcher M.J., Cantor H. Eta-1 (osteopontin): an early component of type-1 (cell-mediated) immunity. Science. 2000. vol. 287. no. 5454. P. 860-864.

36. Peilot H., Rosengren B., Bondjers G., Hurt-Camejo E. Interferon-gamma induces secretory group IIA phospholipase A2 in human arterial smooth muscle cells. Involvement of cell differentiation, STAT-3 activation, and modulation by other cytokines. J Biol Chem. 2000. vol. 275. no. 30. P. 22895-22904.

37. Hansson G.K., Holm J. Interferon-gamma inhibits arterial stenosis after injury. Circulation. 1991. vol. 84. no. 3. P. 1266-1272.

38. Shapouri-Moghaddam A., Saeed Modaghegh M.H., Rahimi H.R., Ehteshamfar S.M., Tavakol Afshari J. Molecular mechanisms regulating immune responses in thromboangiitis obliterans: A comprehensive review. Iranian Journal of $\mathrm{Ba}$ sic Medical Sciences. 2019. vol. 22. no. 3. P. 215-224.
39. Liu J., Lin J., He S., Wu C., Wang B., Liu J., Duan Y., Liu T., Shan S., Yang K., Dong N., Ji Q., Huang K., Li D. Transgenic Overexpression of IL-37 Protects Against Atherosclerosis and Strengthens Plaque Stability. Cell Physiol Biochem. 2018. vol. 45. no. 3. P. $1034-1050$

40. Shimizu K., Shichiri M., Libby P., Lee R.T., Mitchell R.N. Th2-predominant inflammation and blockade of IFNgamma signaling induce aneurysms in allografted aortas [published correction appears in J Clin Invest. 2004 Sep;114(5):739]. J Clin Invest. 2004. vol. 114. no. 2. P. 300-308.

41. Geng Y.J., Henderson L.E., Levesque E.B., Muszynski M., Libby P. Fas is expressed in human atherosclerotic intima and promotes apoptosis of cytokine-primed human vascular smooth muscle cells. Arterioscler Thromb Vasc Biol. 1997. vol. 17. no. 10. P. $2200-2208$.

42. Ye D., Wang Z., Ye J., Wang M., Liu J., Xu Y., Jiang H., Chen J., Wan J. Interleukin-5 levels are decreased in the plasma of coronary artery disease patients and inhibit Th1 and Th17 differentiation in vitro. Revista Espanola De Cardiologia (English Ed.). 2020. vol. 73. no. 5. P. 393-402.

43. Libby P., Kobold S. Inflammation: a common contributor to cancer, aging, and cardiovascular diseases-expanding the concept of cardio-oncology. Cardiovasc Res. 2019. vol. 115. no. 5. P. $824-829$. 